\title{
Translation issues
}

\author{
Mihrije Maloku-Morina
}

\author{
University of Prishtina \\ E-mail: mirije_mm@hotmail.com
}

\section{Doi:10.5901/ajis.2012.v2n4p163}

\section{Abstract:}

\begin{abstract}
A pure language, certain, sententious, fluently, with a rich vocabulary, understandable, articulated, certainly isn't just brilliant and attractive, but it is a sign which shows a high level of civilization. It is obvious that translation plays an important role in human communication. From ancient time up to now, there have been debates about translation. Through translation we understand others and their civilization, therefore, we are interested to do it carefully and sincerely, because mistakes in this field may be disastrous. The meaning of culturally marked words is often difficult to understand without cultural knowledge and poses translation problems, particularly when the words are associated with cultural domains. Words encoding cultural information are difficult to translate since they involve cultural knowledge and a cultural background. Each language describes the world in a different way. Translators need to be well informed of two languages, and need, ideally to be familiar with the subjects of the texts they are translating. Just anything else, also translators can face several problems in translation. It is good to list these problems that we are likely to come across while translating and what strategies to use to overcome these problems. One of the problems which are associated with culture relates to metaphors, emotive and stylistic, lexical, morphological, terminological, words borrowed from other languages, linguistic, cultural, orthographical, syntactic differences etc.
\end{abstract}

Key words: translation, literature, language, metaphors, emotive, stylistic.

\section{Introduction}

It is actually believed that, of all types of translation, literary translation lets one consistently share in the creative process of translation (Landers 2001: 4-5). Literary translations seem to have become so important that the very concept of translation tends to be restricted to literary translation in comparison with other types of translation and other texts.

- First, literary texts - distinguished from non-literary texts are characterized by rhetorical and aesthetic value, which is the essence expected to be captured and maintained in a literary translation. For example, unlike, standard language, literary poetic languages has the feature of foregrounding. To reproduce the rhetorical and aesthetic value is one of the main tasks for literary translations.

- Second, in literary translation the form interlinks with the content; while in non-literary translation the content may be considered detachable from the form or structure. An impressive illustration of this view point is the freight train analogy (Landers, 2001: 7): "In technical translation the order of the case is inconsequential if all the cargo arrives intact. In literary translation, however, the order of the cars - which is to say the style - can make the difference..." Poetry oppositely indicates the fact that the form make sense. In poetry devices such as assonance, alliteration, onomatopoeia, rhythm, verse, metre, and rhyme are sometimes used to achieve musical or incantatory effects. Likewise, in prose a certain linguistic feature or level can also have a certain textual function.

- Third, literary translators' choices of wording are highly dependent on the target language (TL) and culture. Literary texts are solidly rooted in the source language (SL) and culture, yet due to linguistic or cultural differences, literal translations might fail to gain acceptability. There are a set of issues potentially impacting the translators' choices: translations texts, translators, and institutional factors 
(including extensive cultural factors), among which linguistic and cultural differences are the main factors. How to cope with the linguistic and cultural differences is a crucial question for literary translators.

- Fourth, a consideration of the target audiences is another important issue in literary translation. Literary translation always has a readership which is likely to be quite different from the one the writer originally had in it. A "good" translation of any text from any period will, to some extent, only be "good" in the context of a particular audience at a particular time and place.

- Last but not least, literary translation is a complicated act, and to this effect there is no definite correct translation yet there is a proper or an appropriate translation according to certain criteria or from a certain perspective.

Translation is an artistic communication between the author, the translator, and the reader, and the selection of words by translator is a core act in the process of translating as communication. Translation is a communicative act, and literary translation is especially an artistic communication. "Literature is both the condition and the place of artistic communication between senders and addressees, or the public" (Basnet, 2002: 83). In this communication process, the translator has first to read, comprehend, and interpret the source text, then to represent it in a different medium. Selection is a core act in the process. Translating can be compared with a game with complete information, like chess, where every next move takes account of all previous moves.

Literary translation includes translating of fiction, poetry, drama, etc. in literary translation, a translator is supposed to pay much attention to the language arts. To transfer the information is not the only purpose of literary translation, to create an equivalent form of art is also an important part of task of the translator. In this sense, a translator who is engaged in literary translation is supposed to be equipped with not only at least two languages but also relevant knowledge.

\begin{abstract}
Translating literary works is, perhaps, always more difficult than translating other types of text because literary works have specific values called the aesthetic and expressive values. The aesthetic function of the work shall emphasize the beauty of the words (diction), figurative language, metaphors, etc. while the expressive functions shall put forwards the writer's thought (or process of thought), emotion, etc. and the translator should try, at his best, to transfer these specific values into the target language (TL). As one genre of literature, poetry has something special compared to others. In a poem, the beauty is not only achieved with the choice of words and figurative language like in novels and short stories, but also with the creation of rhythm, rhyme, meter, and specific expressions and structures that may not conform to the ones of the daily language. In short, the translation of poetry needs "something more" than translating other genres of literature. This simple writing will present in brief some considerations in translating poetry the eight-stage procedure to translate a poem. (Hariyanto: http://www. Translationdirectory.com/article 638.htm)
\end{abstract}

Regarding those problem of translating the work of literature, some reasons which are common in doing the literary translation because it gives the translator consistently share in the creative process, it also allows the translator to be recognized as part of the literary world which offers many intellectual rewards, it lets the translator expand the potential readership of a literary work and also allows the translator gain prestige, helps develop longlasting relationships, and give them access to different worlds. Considering the benefit of translating the work of literary translator has many things to do towards the translation. The first thing to be considered by the translator is that his/her familiarity to the literary work. He/she should be aware of the stylistic elements beside the message given by the work of the literature. In addition to the thorough mastery of the source language, the literary translator must possess a profound knowledge of the target language (for both the language and culture). The literary translator must command tone, style, flexibility, inventiveness, knowledge of the SL culture, ability to glean meaning from ambiguity, and ear for sonority and humility. 


\section{Culture -Specific Items in Literary Translation}

Through translation we understand others and their civilization, therefore, we are interested to do it carefully and sincerely, because mistakes in this field may be disastrous. The meaning of culturally marked words is often difficult to understand without cultural knowledge and poses translation problems, particularly when the words are associated with cultural domains.

Words encoding cultural information are difficult to translate since they involve cultural knowledge and a cultural background. Each language describes the world in a different way. Translators need to be well informed of two languages, and need, ideally to be familiar with the subjects of the texts they are translating.

Translation plays an important role in filling the gaps between different cultures and nations. Literary translations in particular help these different nations reach a universal culture on a common ground. A good translation is not simply concerned with transferring the propositional content of the source language text $(\mathrm{SLT})$, but also its other pragmatic features. The attention given to pragmatic facts and principles in the course of translation can enhance the understanding of the text and improve the quality of translation.

Since the concept of culture is essential to understanding the implications for literary translation and culture-specific items in translation, many translation theorists have dealt with definition of culture. In 1984 Larson defines culture as 'a complex beliefs, attitudes, values, and rules which a group of people share" (Larson 1984: 431). He notes that the translator needs to understand beliefs, attitudes, values, and the rules of the SL audience in order to adequately understand the ST and adequately translate it for people who have a different set of beliefs, attitudes, values, and rules. In 1998, Newmark remarks that culture is "the way of life and its manifestations are peculiar to a community that uses a particular language as its means of expression" (Newmark 1998: 94). Here, he asserts that each language group has its own culturally specific features.

Indeed, one of the most difficult problems in translating literary texts is found in the differences between cultures. People of a given culture look at things from their own perspective. Larson notes that "different cultures have different focuses. Some societies are more technical and others less technical. Therefore, if the $\mathrm{SL}$ text originates from a highly technical society it may be much more difficult to translate it into the language of a nontechnical society. However, in the case of similar cultures the conditions are not the same. When the cultures are similar, there is less difficulty in translating. This is because both languages will probably have terms that are more or less equivalent for the various aspects of the culture. When the cultures are very different, it is often difficult to find equivalent lexical items.

Translation plays an important role in increasing awareness and understanding among diverse cultures and nations. Literary translations in particular help these different cultures reach a compromise. The increasing interest in the literature of other languages has required a more studious regard for the problems of literary translation. A translator deals with a text which involves linguistic, pragmatic and cultural elements. Such problems often pose problems to target readers. More often than not, translators pay more attention to linguistic and cultural elements than to pragmatic aspects of a source text.

\section{Pragmatic approach}

Literary translation is a type of translation which distinguished from translation in general. A literary translation must reflect the imaginative, intellectual and intuitive writing of the author. In fact, literature is distinguished by its aesthetics. Moreover, literary translations must reflect all the literary features of the source text such as sound effects, morphophonemic selections of words, figures of speech...etc (Riffaterre 1992: 294-205).

Basically, translation consists of transferring the meaning of the source language into the target language. That process is done by changing the form of the first language to the form of the second language. Thus, it is meaning which is being transferred and must be held constant. But what type of meaning a translator should transfer! Generally, linguists distinguish different types of meaning. When it relates language to events, entities, etc., it is called referential / denotative meaning. When it relates language to the mental state of the speaker, it is called attitudinal / connotative / expressive meaning. Any level in language has its 
own significance because it plays a role in the total meaning, e.g phonetic, lexical, grammatical, semantic and pragmatic meanings.

In addition to the pragmatic approach to translation there are other approaches to translation that may involve other aspects such as structural, cultural, functional etc. However, recent translation approaches can be divided into linguistic-based approaches and cultural approaches. On the one hand, linguistic-oriented approaches have been accused of being limited in their explanation because they do not consider the social cultural values in translation. They have been also for being criticized for being directed to specialist linguists. They are repressive (Venuti 1998: 1-26). On the other hand, cultural approaches highlight cultural differences between the source text and the target text. In fact, both linguistic and cultural studies of translation are important. "Translation is a kind of activity which inevitably involves at least two languages and two cultural traditions" (Toury2000:200).

In fact, translation is a complex entity, which involves a large number of variables other than reproduction of meaning, in this regard, in the process of translating a text the translator should not know only languages involved, but also their cultures and rhetorical traditions (Enkvist 1991: 14-15).

Different theories and models can be counted in the field of translation. Bell (1991"23-24) distinguishes between the theory and the model. He shows that a theory explains a phenomenon and is communicated to others in the form of a model. A model is "an attempt at a description rather than explanation" (1991: 26). The term "approach" might be more appropriate (1991: 27). Vinay and Drablent (1958: 84) recognize two types of translations:

1- Direct Translations where the linguistic features of the SLT are replaced by their equivalents in the TLT, and

2- Oblique translations where complex methods are used to render certain stylistic effects.

By and large, types of translation are radically diverse but depend mainly on a central concept, that is, equivalence. Therefore, many translation theorists define translation in terms of equivalence relation; relation between SLT and TLT. The translator's objective and the text type determine the type of equivalence used in the process of translation. Equivalence is a relationship of equality between the SLT and TLT. It is worth pausing for a moment to wonder which type of equivalence should be given priority. Translation theorists answered this question differently. Vinay and Darblent (1958) believe that if there is no synonymy in the bilingual dictionary, the translator has to restort to what they called "situational equivalence"; creating a new situation in the target context (Vinay and Darblent 2000: 91). Then, Jakobson (1959) introduces the term "equivalence in difference" (Jakobson 2000: 114). They licensed the use of non-linguistic methods such as loan-translation and neologisms.

Nida (1964) introduces two types of equivalence: formal and dynamic; the former focuses on the form and content of the message while the latter on producing equivalent effect.

Conversely "equivalence" consists of many countenances; for instance, it is an essential condition for translation, an obstruction to advancement in Translation Studies, or helpful category for analyzing translations. Sometimes, it is "damaging" (Gentzler, 1993) or "irrelevant" (Snell-Hornby, 1988: Chapter 5). The domain of equivalence covers linguistic units such as morphemes, words, phrases, clauses, idioms and proverbs. "Most translators are used to it (equivalence) rather than because it has any theoretical status" (Baker, 1992: 5-6). Catford (1965) thinks that the central problem of translation practice is that of finding T.L. (target language) equivalents. A central task of translation theory is therefore that of defining the nature and conditions of translations equivalence (p.21).

The translator, through using equivalence approaches, also endeavour to influence their readers by the "standard translation". Yet, the notion of equivalence creates several problems since we can interpret it in miscellaneous manners. Both the words as well as context are considered in equivalence. In this connection, Catford (1965) simply puts forward that translation is the "substitution or replacement of textual materials in one language by equivalent textual material in another language" (p.20). But, his linguistic theory of translation was not (and is not) accepted liberally by many. 
The sentences does not consist only of a statement but aims at something beyond what it actually says. Within a literally text, sentences always indicate something that is to come and their particular content foreshadows the structure. There may be a loss of element if the translators handles sentences for their definite content only.

\section{Cultural terms}

Many scholars agree with the fact that language is an expression of culture and individuality of its speakers and have, hence, deeply examined cultural terms, as well as the problems involved in their translation when there is a lack of equivalence between two languages and cultures (Kade, Kutz, Nord, Rabadan, and Venuti, for example).

For such cultural aspects have been offered many classifications (Baker, Katan, Mayoral, Moilina, Newmark etc). Newmark puts forth his classification of foreign cultural words, establishing five categories:

a. Ecology (flora, fauna, winds, climate, etc)

b. Material culture (food, clothes, houses, towns, transport)

c. Social culture (work and leisure)

d. Organizations, customs, activities, procedures or concepts (which include artistic, religious, political and administrative subcategories)

e. Gesture and habits

It is true that translating cultural terms causes many translation difficulties, but this does not mean that they cannot be translated. In fact, along some translation scholars, particularly those of the Leipzig school (Kade, Jager, Neubert), all languages can say (or are capable of saying) the same things; but, as a rule, all of them say it in a different way. Indeed, should two languages say it in the same way, then we would not be speaking of two languages, but of one and the same language. The translator can have recourse to several devices for solving the problem of bridging the gap across cultures, providing that he/she is culturally aware of those differences. He/she can rely on various procedures, techniques or strategies to deal with such translation problems.

The translator can coin or borrow the term from the SL into the TL, or adapt it to suit the TC. It is also possible to explain the conceptual differences in a footnote or in the text itself, and so on. It is up to the translator to choose the most suitable way to render it in the $\mathrm{TL}$, and for the $\mathrm{TC}$, depending on the aim, the time available, the potential readers, etc. of the translation.

\section{Translation Procedures and Strategies}

Translation strategies are usually defined as the procedures leading optimal solution of a translation problem. The procedures or strategies that are usually mentioned in academic publications serve both to analyse and catalogue translation equivalence and to improve the acquisition of translation competence, since knowing and comparing them is definitively necessary to obtain an adequate translation.

Some of the basic translation procedures are: adaptation, borrowing, equivalence, calque, compensation, literal translation etc.

Adaptation: is used in those cases in which the type of situation being referred to by the SL message is unknown in the TC and translators create a new situation that can be described as situational equivalence. There are situations in which adaptation seems, to some extent necessary: in advertising slogans, or children's stories, for example. In other cases there are certain conventions, more or less generalized, as regards adapted translations of foreign cultural elements in the TL. This applies, for instance, to weights and measures, musical notation, generally accepted titles of literary works or geographical names, etc. the basic goal of the translator when trying to "adapt" the translation is to have a similar effect on the TL readers, "domesticating", in a way, the cultural terms. 
Borrowing: a term is taking a word or expression straight from another language, without translation. The procedure is normally used when a term does not exist in the TC, or when the translator tries to get some stylistic or exotic effect. It can be "pure", if there is no change of any kind in the foreign term (broker, chip, clown, stop etc), or "naturalized", if the word has some change in the spelling, and perhaps some morphological or phonetic adaptation (as in disketë "disquete", ristartim "restart" etc).

Equivalence: according to Vinay and Dalbernet, equivalence refers to a strategy that describes the same situation by using completely different stylistic or structural methods for producing equivalent texts. This basically means that the transalator uses a term or expression recognized as an established equivalent in the TL.

Calque: could be described as a literal translation (either lexical or structural) of a foreign word or phrase. It could actually be considered a special type of loan or borrowing, since the translator borrows the SL expression or structure and then transfers it in a literal transaltion, as in the case of shocked "I shokuar", stressed "I stresuar", etc.

The difference between loan/borrowing and calque is that the former imitates the morphology, signification and phonetics of the foreign word or phrase, while the letter only imitates the morphological scheme and the signification of that term, but not its pronunciation.

Compensation: the aim of compensation is to balance the semantic losses that translation involves (either in the content of the message or its stylistic effects). Compensation introduces a SL element of information or stylistic effect in another place in the TL text because it cannot be reflected in the same place as in the SL: the translation of dialects, irony politeness values etc. in the cases of Albanian-English translation, we could mention, for example, the familiarity or formality of "ti" dhe "ju". Both words are translated into English as "you", so the translator will have to express degrees of formality in different ways, maybe compensating by using other English words of the formal and informal registers, in order to preserve the same level of formality.

Literal translation: or word by word, occurs when a SL word or phrase is translated into a TL word or phrase, without worrying about style, but adapting the text to the TL syntactic rules, with minimal adjustments, so that it sounds both correct and idiomatic (word order, functional words etc.).

\section{Solutions for the Translators of Literary Prose}

Initially, the translation of literary works - novels, short stories, plays, poems, etc.- is considered a literary recreation in its own right. However, as far as the solutions, are concerned, the prose translators should start with the careful adherence to the following principles:

1. A great understanding of the language, written and verbal, from which he is translating i.e. the source language;

2. An excellent control of the language into which he is translating i.e. the target language;

3. Awareness of the subject matter of the book being translated;

4. A deep knowledge of the etymological and idiomatic correlates between the two languages; and

5. A delicate common sense of when to metaphrase or "translate literally" and when to paraphrase, in order to guarantee exact rather than fake equivalents between the source- and target language texts.

Moreover, the prose-translators can unite some of the following methods to deal with the translation problems efficiently.

1. Back Translation. It is one of the most familiar practices used to search for equivalents through:

a. The translation of items from the source language to the target language.

b. Free translation of these back into the source language.

2. Conference with other people: Discussions about the use and meaning of words with bilingual people around the table to make decisions about the best terms to use.

3. Interviews or Questionnaires or Any Kind of Tests: These are used to remove translation-related difficulties. 
Now, the problems in translating prose can be solved much if the prose-translator is both bilingual and bicultural. Thierry (1978) states that "perfect bilingual" (p.145) implies two things:

1. One speaks both the languages consistently well.

2. One has two mother tongues.

Correspondingly, a natural translation must also be in reference to the situation of the specific message, which could include not only the grammatical and lexical elements but also detailed matters such as intonation and sentence rhythm. However, Harris and Sherwood (1978) are of the view that a natural translator has to go through the following stages:

1. "Pre-translation", where the translator typically uses single words,

2. "Auto-translation", whereby the translator translates to others what he has said or written himself,

3. "Transduction", whereby the translator works as a mediator between two other people. (pp.165-166)

Additionally, by the prose-translators should follow the six principles presented Hillaire Belloc (1931):

1. The translator must regard the work as an integral unit and translate in sections.

2. The translator must decode "idiom by idiom".

3. The translator ought to translate "intention by intention" hinting the heaviness a particular term might contain in a meticulous situation in the S.L that would be asymmetrical if translated exactly into the T.L

4. Words or formations that may possibly come out to match up in both S.L and T.L but actually do not. For example "demander - to ask ", translated incorrectly as to "demand".

5. The translator is supposed to 'alter courageously".

6. The translator must never overstate.

Through these six principles, Belloc suggests the translator to view the prose text as a structured "whole"; if the translator thinks in this manner, then it will be easier for him to translate and the translated text will be a good one, besides, the translator must not forget the stylistic and syntactical requirements of the T.L. many theorists believe that the translator has the right to change the text much in the translation procedure. In fact, the translator has the liberty to do it intentionally because, while translating, he has to keep the T.L stylistic and idiomatic norms in mind. If he does so, then the T.L readers will be able to enjoy the text more.

The prose-translator must not think that any bilingual individual is able to produce satisfactory or even high-quality document translations simply because he is a fluent speaker of a second language. The ability, skill and even the basic mental processes required for bilingualism are mostly different from those required for translation. Primarily, the prose-translators must be able to read, understand and cling to somebody else's thoughts, then translate them accurately, completely and without omission. If they are able to do so, the readers will get the original meaning. Normally, the translators think that the best translations are produced by persons who are translating from their second language into their native language, because it is unusual for someone who has learned a second language to have total fluency in that language.

However, the prose-translator should not worry much about the "loss of meaning", which may occur if the text describes a situation, which has elements that are unusual to the natural environment, institutions and culture of its language area, since the transference to the translator's language can only be estimated.

Since translation is simultaneously a theory and a practice, the translators, beside dealing with the difficulties inherent to the translation of prose, must think about the artistic features of the text, its exquisiteness and approach, as well as its marks (lexical, grammatical or phonological). However, the translators can try to find equivalence in translation and show the cautious nature of their assertions accordingly and request the readers to join and select which translation renders the thoughts, notions and words of the original text correctly.

\section{Problems Which Can Occur Due To Bad Translation}

The most basic form and reason of misunderstanding, is not able to understand what the other person is saying. Even, if you understand the word, then you do not understand the meaning sometimes. This creates 
confusion and even a rift between two people or their thinking. This is an ineffective communication and it happens all the time around us. These same problem apply in the written world too, when you read a work that has been translated from one language to another. The further problem is that, in this case, the reader cannot straight to the translator and demand an explanation or to express his confusion. So, this demands from translator to produce a good and well-translated document. Only a professional translator can do it.

There are many problems that can occur due to a badly-translated work. It can start with something seemingly small. There are many fields where a professional translator is needed and without an efficient person doing your translation work, you can end up in a legal trouble. Translator should be experienced and adept at the language he is supposed to be translating in and from, he should be sensitive to the document and understands the need of translation.

Just like anything else, one can encounter several problems in translation. It is wise to list those problems so that one would know what are the problems that he/she is likely to come across while translating and what strategies to use to overcome these problems. Since I work both English and Albanian languages, the following problems are listed with these two languages in mind.

- Words carry different meanings: English words are known for being polysemous. Words may be ambigious, and thus, be mistranslated if interpreted out of context. Also, words can acquire different meanings across languages like denotative, connotative, collocational, etc.

- There are emotive and stylistic differences: words mean different things for different people: words may differ in their emotive values or stylistically, i.e. words may be formal, neutral or informal.

- There are lexical differences: words in languages have many synonyms, antonyms etc. this may often vary across languages.

- There are morphological differences: the world is changing quickly, so new words and meanings are being coined to name the new concepts and objects. This may be true for one language, while the other language may not have an equivalent word readily available or easily accessible. Also, new word-formation processes are being developed and implemented. Moreover, languages have different ways of using affixes (prefixes, suffixes and infixes).

- There are terminological differences: emphasizing the previous statement, equivalents are not always found easily for new terms in recent developments of telecommunications, regulatory, science, technology, computer, internet etc. This is because new concepts and objects are constantly appearing and emerging. This may cause terminological inconsistencies.

- There are words borrowed from other languages: as is the case in English which tends to borrow a lot from other languages like French, Greek and Latin. It may be difficult to understand these words if one is not familiar with the language.

- There are cultural differences: this is the issue of what is acceptable in one language and what is frowned upon in another language. This may sometimes depend on the context, place, users etc.

\section{Translators}

A competent translator shows the following attributes:

- A very good knowledge of the language, written and spoken, from which he is translating (the source language);

- An excellent command of the language into which he is translating (the target language);

- Familiarity with the subject matter of the text being translated ;

- A profound understanding of the etymological and idiomatic correlates between the two languages; and

- A finely tuned sense of when to metaphrase ("translate literally") and when to paraphrase, so as to assure true rather than spurious equivalents between the source-and target-language texts.

A competent translator is not only bilingual but bicultural. A language is not merely a collection of words and of rules of grammar and syntax for generating sentences but also a vast interconnecting system of 
communications and cultural references whose mastery, writes linguist Mario Pei "comes close to being a lifetime job.

The complexity of the translator's task cannot be overstated; one author suggest that becoming an accomplished translator - after having already acquired a good basic knowledge of both languages and cultures - may require a minimum of ten years' experience. Viewed in this light, it is a serious misconception to assume that a person who has fair fluency in two languages will, by virtue of that fact alone, be consistently competent to translate between them.

We can say, then, that the meaning of a literary text is bounded by two elements: The meaning of the text itself and the author's concepts, and is, in a sense, the product of two. It becomes clear, then, that in aiming for an adequate translation of the author's intention in the SL message, the translator should consider not only the meaning of the work but also the author's concepts which govern its meaning, i.e. the reality behind it.

\section{Conclusion}

Since we consider literature as a product of the dominant ideology, it is obvious that sign system cannot be assumed to be understood by everyone, for language is a dynamic and inclined to change quite rapidly. Furthermore, in most societies literary translation seems to have become so prominent that the very concept of translation tends to be restricted to literary translation and other texts.

One of the most difficult problems in translating literary texts is found in the differences between cultures. People of a given culture look at things from their own perspective. Indeed, one of the most difficult problems in translating literary texts is found in the differences between cultures. A translator who uses a cultural approach is simply recognizing that each language contains elements which are derived from its culture that every text is anchored in a specific culture, and that conventions and reception vary from culture to culture.

\section{References}

Baker, M. (1992). In other words: A Coursebook on Translation. London and New York: Routledge.

Bassnet, S. (1980). Translation Studies. London: Methuen\&Co. Ltd.

Belloc, H. (1931). On Translation. Oxford: The Clarendon Press.

Catford, J.C. (1965). A Linguistic Theory of Translation. London: Oxford University Press

Eagleton, T. (1977). Translation and Transformation. Stand, 19 (3).

Landers, C. E. (2001) Literary Translation: A Practical Guide, New Jersey University Press: Multilingual Matters

Newmark, P. (1988). A Textbook of Translation. New York \& London: Prentice Hall.

Newmark, P. (1988). More Paragraphs on Translation. New Jersey University Press: Multilingual Maters.

Nida, E.A. and C.R. Taber (1969) The Theory of Practice of Translation. Leiden: E.J. Brill.

Nord, C. (1997) Translating as a Purposeful Activity: Functionalist Approaches Explained. Manchester: ST. Jerome.

Snell-Hornby, M. (1988). Translation Studies: An Integrated Approach. Amsterdam: John Benjamin.

Therry, C. (1978). True Bilingualism and Second Language Learning. In D. Gerver\&H. Sinaiko (Eds.), Language, Interpretation and Communication. New York: Plenum Press.

Venuti, L. (1995). The Translator's Invisibility. A History of Translation. London and New York: Routledge.

Venuti, L. "Call to Action", in The Translator's Invisibility, 1994, A history of translation, London and New York: Routledge.

Vinay, J.P., \&Darbelnet, J. (1995). Comparative Stylistics of French and English: A Methodology for Translation (J.C.Sager\&M.J. Hamel, Trans.). Amsterdam/Philadelphia: John Benjamins.

Pei, M. The Story of Language, p.424. 
